\title{
Determinação de blocos de partição em maciços rochosos através de planos de descontinuidades com uso de VANTs
}

\author{
Alfredo César Vale de Araújo ${ }^{1 *}$ \\ Silas Leonardo Dias Vasconcelos ${ }^{1}$ \\ Jorge Luiz Valença Mariz ${ }^{2}$ \\ Júlio Cesar de Souza ${ }^{1}$ \\ Márcio Luiz de Siqueira Campos Barros ${ }^{1}$
}

\section{Resumo}

Maciços rochosos são definidos como conjunto de blocos de rocha justapostos e articulados, limitados pelo arranjo de planos de descontinuidades (fraturas, juntas, falhas e foliações), cujas famílias afetam diretamente o aspecto dos maciços quanto às alternativas de métodos de lavra. A aerofotogrametria empregada no trabalho pelo uso de VANT (veículo aéreo não tripulado) foi adequada para auxiliar nas informações adquiridas com a captura das imagens aéreas e o levantamento do scan face nas bancadas norte e leste de uma pedreira para produção de agregados para a construção civil localizada na zona da mata do estado de Pernambuco. Após a criação do modelo, com o auxílio de uma ferramenta CAD e do diagnóstico das fraturas mais destacadas, com análise de estatística descritiva, projeções estereográficas pela rede de wulff; e o Diagrama de Rosetas dos planos de descontinuidades, se fez a interpretação dos blocos de partição das bancadas norte e leste do maciço estudado. O uso do vant, no trabalho, enriqueceu o tratamento dos dados levantados do scan face e propiciou a identificação dos blocos de partição, bem como outras zonas de fraqueza no maciço, que habilitam possíveis alterações na interpretação de projetos de engenharia.

Palavras-chave: Blocos de partição; Descontinuidades; VANT; Scan face.

\section{Determination of partition blocks in rock masses through descontinuity plans with use of UAV}

\begin{abstract}
Rocky massifs are defined as a set of juxtaposed and articulated blocks of rock, limited for the discontinuity plans (fractures, joints, failures and foliations), whose families directly affect the appearance of the massifs in terms of alternative open pit mine planning. Aerophotogrammetry employed at work for the using UAV (unmanned aerial vehicle) was adequate to assist in the information acquired with the capture of aerial images and lifting the scan face, on the north and east benches of a quarry for the production of aggregates for civil construction located in the forest area of the state of Pernambuco. After creating the model, with the aid of a CAD tool and the diagnosis of the most highlighted fractures, with descriptive statistical analysis, stereographic projections through the wulff net and and the Rosette Diagram of the discontinuity plans, the partition blocks of the north and east benches of the studied massif were interpreted. The use of vant at the paper, increased the level the work the treatment of data collected from scan face and provided the identification of the partition blocks, as well as other areas of weakness in the massif, that enable possible changes in the interpretation of engineering projects.
\end{abstract}

Keywords: Partition blocks; Discontinuities; UAV; Scan face.

${ }^{1}$ Departamento de Engenharia de Minas, Universidade Federal de Pernambuco-UFPE, Pernambuco, Recife, PE, Brasil.

${ }^{2}$ Departamento de Engenharia de Minas, Universidade Federal do Rio Grande do Sul-UFRGS, Rio Grande do Sul, Porto Alegre, RS, Brasil.

*Autor correspondente: cesarvale_araujo@hotmail.com

2176-1523 C 2020. Araújo et al. Publicado pela ABM. Este é um artigo publicado em acesso aberto (Open Access) sob a licença Creative Commons Attribution, que permite uso, distribuição e reprodução em qualquer meio, sem restrições desde que o trabalho original seja corretamente citado. 


\section{Introdução}

Do ponto de vista da engenharia, maciços rochosos são definidos como conjunto de blocos de rocha justapostos e articulados, limitados pelo arranjo de planos de descontinuidades (fraturas, juntas, falhas e foliações), superfícies responsáveis pelo comportamento (estabilidade e deformabilidade) e aspectos dos maciços (formas geométricas irregulares) que, por apresentarem orientações espaciais, promovem um comportamento anisotrópico [1,2]. É a escala da porção do maciço analisado em relação à obra considerada que define a validade de se admitir o meio homogêneo ou heterogêneo, isotrópico ou anisotrópico, contínuo ou descontínuo, no âmbito de um estudo qualquer [3].

As famílias de descontinuidades afetam diretamente o aspecto dos maciços rochosos ampliando as alternativas de lavra de blocos [4,5], a Figura 1 mostra a possibilidade de aplicação em jazidas de rochas ornamentais para remoção de blocos o que auxiliaria na extração de jazidas de rocha ornamental.

Alguns dos campos de aplicação, com influência dos planos de descontinuidade, podem ser apreciados na mineração com uso de explosivos, Figura 2a, na construção civil de túneis, Figura $2 \mathrm{~b}$, e estruturas de fundações, Figura 2c.

A aerofotogrametria empregando VANTs é adequada para projetos de engenharia que necessitam de informações atualizadas da superfície terrestre, com elevada resolução espacial e para usos relacionados com a coleta de informações frequentes, como: monitoramento de impactos ambientais, na agricultura de precisão, no deslocamento de terra, mapeamento de minas a céu aberto, cadastro urbano, mapeamento de pequenas áreas em projeto de engenharia e no sensoriamento remoto [6].

A necessidade de interpretar os dados coletados com o uso de VANT constituiu um trabalho com o objetivo de apresentar uma alternativa para melhor representar a visualização tridimensional dos blocos de partição, oriundos dos planos de descontinuidade, envolvendo o tratamento de imagens aéreas coletadas in situ, com capacidade de filmagem de 4k e 12 megapixels, realçando as fraturas de interesse (2 a $6 \mathrm{~cm}$ de espessura) descritas como muito

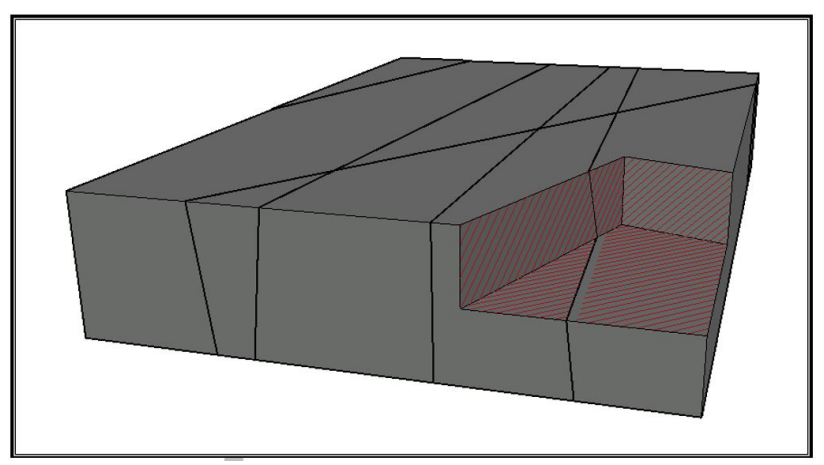

Figura 1. Aplicação em lavra de blocos. moderadamente fechadas de acordo com a ABGE/CBMR nos maciços rochosos [7].

A determinação da linha de varredura nas faces das bancadas dos maciços rochosos (scan face) e as atitudes (sentido, direção e mergulho), cujo mapeamento foi auxiliado pela rede de Wulff, e o tratamento estatístico da distribuição de frequência das fraturas a cada $10 \mathrm{~m}$, delimitaram o surgimento de blocos formados pelo arranjo dos planos de descontinuidades (blocos de partição) e suas devidas representações estereográficas.

A área selecionada para desenvolvimento da pesquisa está inserida no domínio dos complexos granitóides indeformados, onde se encontra o município de Vitória de Santo Antão, na Zona da Mata do Estado de Pernambuco. O maciço rochoso estudado é um granitoide de alta resistência com potencial para produção de brita, encontrado na Pedreira Esperança a partir das coordenadas em UTM 9.101.601,26 S e 255.450,66 W, às margens da rodovia BR-232. O maciço estudado é visualizado pela fotografia aérea na Figura 3.

\section{Metodologia}

A coleta de dados foi efetuada segundo um levantamento através da scan face das faces livres do maciço estudado, por um voo com VANT (Drone Mavic pro), Figura 4, que foi programado no aplicativo Drone Deployed para obtenção de fotos georreferenciadas a cada avanço horizontal pré-determinado na face da bancada. Após a coleta dos pontos, estes foram tratados com o auxílio do software Agisoft Photoscan, onde os pontos serão corretamente posicionados e será elaborado um modelo 3D das bancadas.

Após a criação do modelo, foram identificadas nestes, as famílias de descontinuidades mais persistentes na face mapeada. Com o auxílio de um software CAD e de uma bússola de estrato modelo Clar para geólogo, são verificadas as atitudes das descontinuidades, que podem então ser projetadas no modelo do maciço. Em seguida são plotadas em projeção estereográfica através da linguagem de programação Python, o que permitiu a análise estatística destas descontinuidades e a definição dos blocos de partição das faces do maciço, das dimensões dos blocos e seu correto posicionamento na bancada.

\section{Resultados e discussão}

\subsection{Captura de imagens aéreas e determinação do scan face}

A captura das imagens ocorreu em um posicionamento que abrange a face livre onde será o levantamento do scan face e as bancadas, Figura 5. 


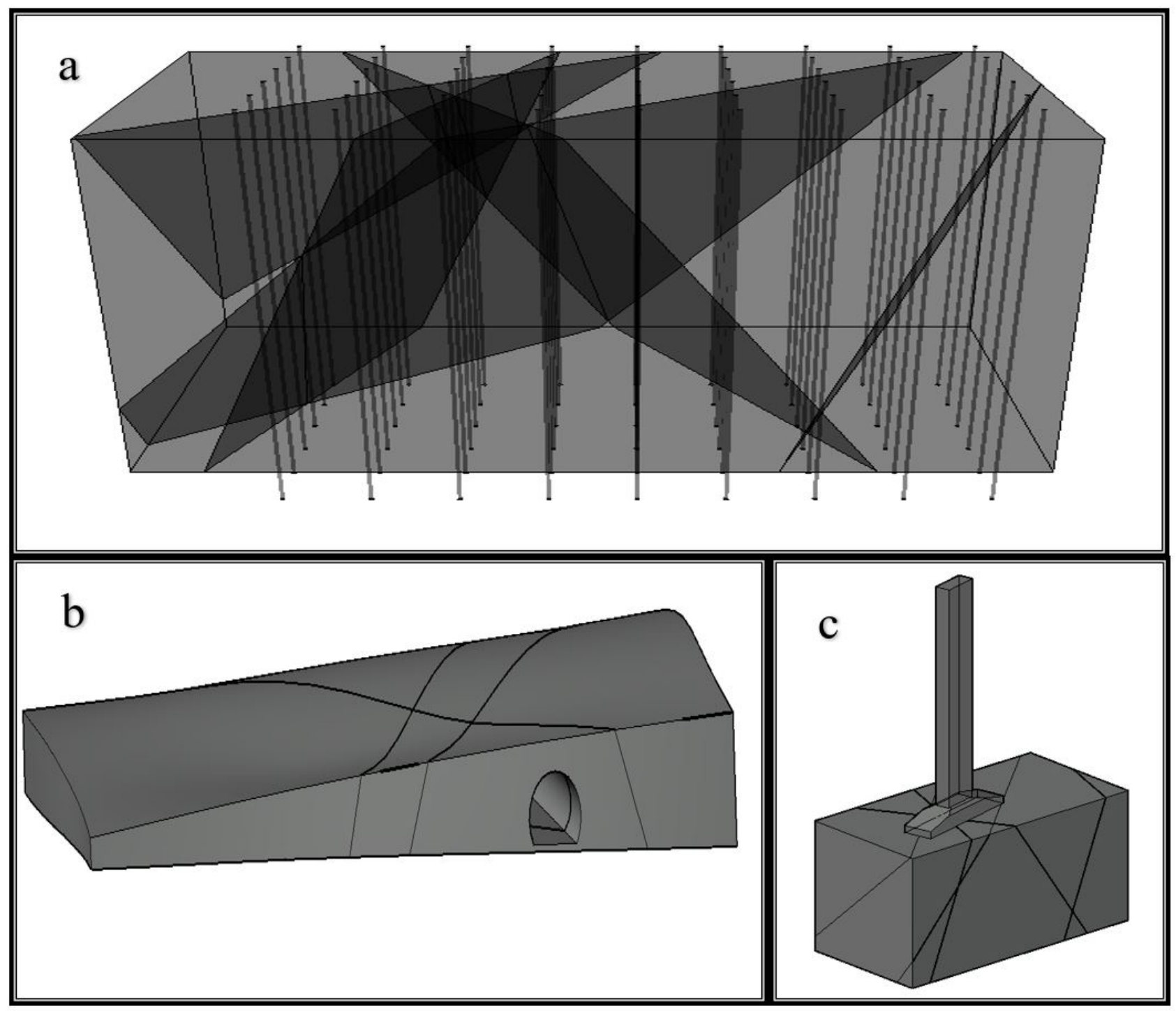

Figura 2. Aplicação no campo da mineração e construção civil. (a) Aplicação em desmonte de rocha com explosivos; (b) Construção de túneis; (c) Estruturas de fundações.

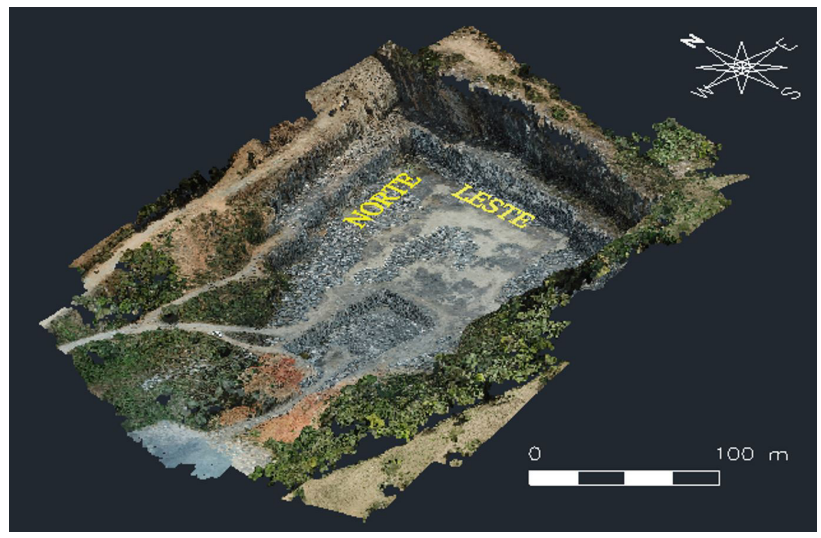

Figura 3. Modelo 3D da área de estudo e suas bancadas ao norte e leste.

O scan face foi determinado em duas frentes de bancadas da pedreira, ao norte onde se encontra uma extensão de 110 metros mesurados no sentido oeste-leste, com duas bancadas de alturas 16m (B1) e 18m (B2), Figura 6.

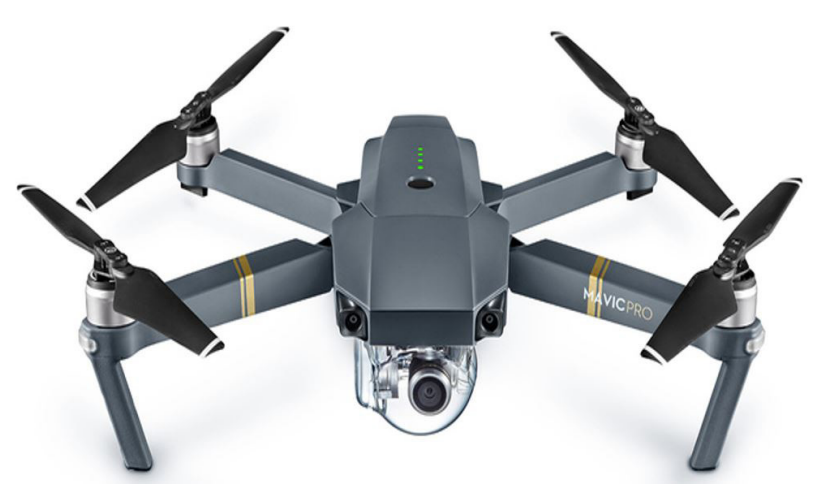

Figura 4. Drone Dj Mavic Pro utilizado no levantamento do scan face e captura das imagens aéreas.

A outra frente levantada foi ao leste onde se encontra uma extensão de 130 metros mensurados no sentido norte-sul, com bancadas de $16 \mathrm{~m}$ (B3) e $30 \mathrm{~m}$ (B4), Figura 7. 


\subsection{Projeção estereográfica das atitudes nas bancadas}

A partir da captura das imagens aéreas, se pode visualizar as descontinuidades de maior destaque no maciço. Pelos levantamentos das atitudes (direção, sentido e mergulho) presentes, em azimute, adquiridos com uso de uma bússola de modelo Clar; as projeções estereográficas pela rede de wulff; e o Diagrama de Rosetas dos planos de descontinuidades, se pode interpretar, Tabela 1, o comportamento das distribuições de estruturas planares e o adensamento dos polos formados, Figura 8.

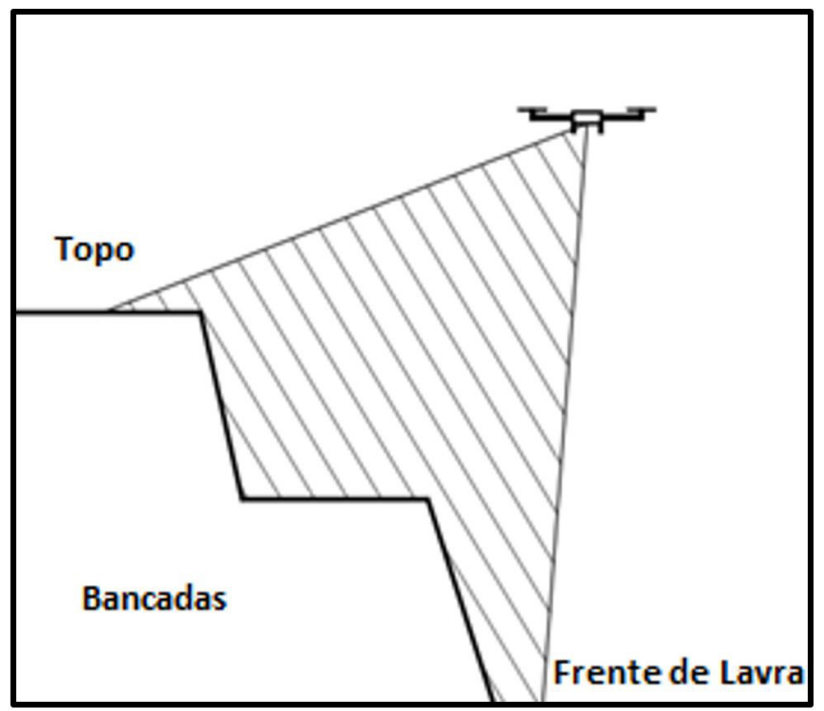

Figura 5. Posicionamento do vant para captura das imagens aéreas e levantamento do scan face.
Nas bancadas ao leste, as projeções estereográficas pela rede de wulff e o Diagrama de Rosetas, dos planos de descontinuidades e o adensamento dos polos, são agrupados na Tabela 2 e ilustrados na Figura 9.

\subsection{Análise estatística}

Através da análise de estatística descritiva, os dados foram agrupados em tabelas que mostram sua distribuição de frequência para melhor fornecer informações sobre a forma de concentração e influência, em sua adjacência, das fraturas ao longo de toda a extensão da bancada.

A frequência relativa, no caso, mostra a frequência de sucesso de um determinado número de descontinuidades em intervalos de classes delimitado. A frequência relativa acumulada aponta a frequência de sucesso até o último intervalo de classe delimitado, como mostram as Tabelas 3 e 4, referentes as bancadas norte e leste, respectivamente.

\subsection{Desenvolvimento dos blocos de partição}

A Figura 9 mostrou uma estimativa do comportamento estrutural das descontinuidades na frente de lavra da bancada norte, onde se constata a distribuição paralela de 3 famílias de descontinuidades compostas por D2, D3 e D4, uma família composta por D6 e D10, e uma família composta pelas descontinuidades D7 e D8. As descontinuidades D6 e D10 se interceptam às demais componentes estruturais ao longo de toda a bancada norte, delimitando as regiões de fraqueza.

Uma melhor análise do potencial geométrico dos blocos de partição formados com os dados adquiridos e tratados, da frente norte, pode ser mostrada na Figura 10, onde se observa uma conjuntura prismática irregular dos blocos.

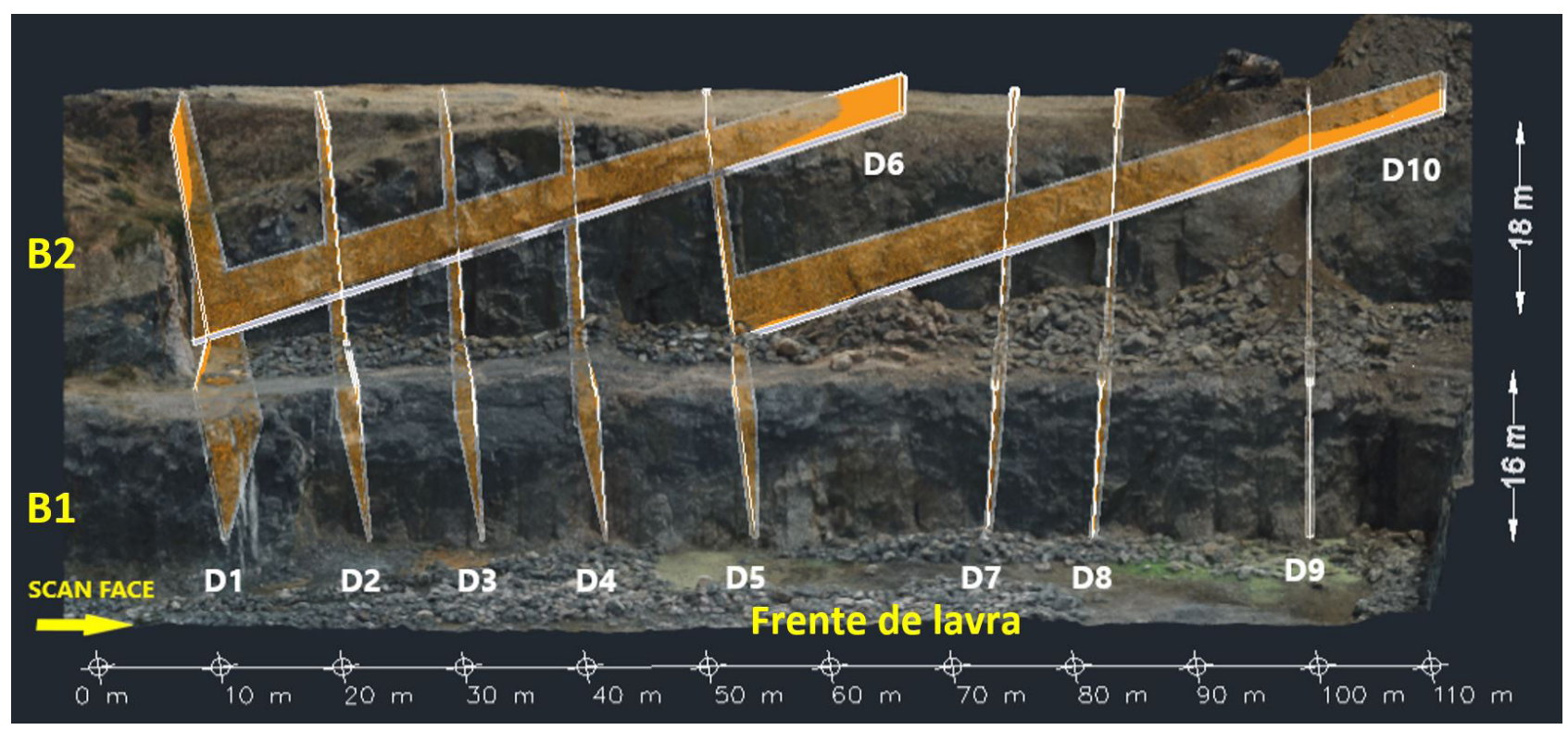

Figura 6. Estimativa do comportamento estrutural das descontinuidades nas bancadas ao norte. 


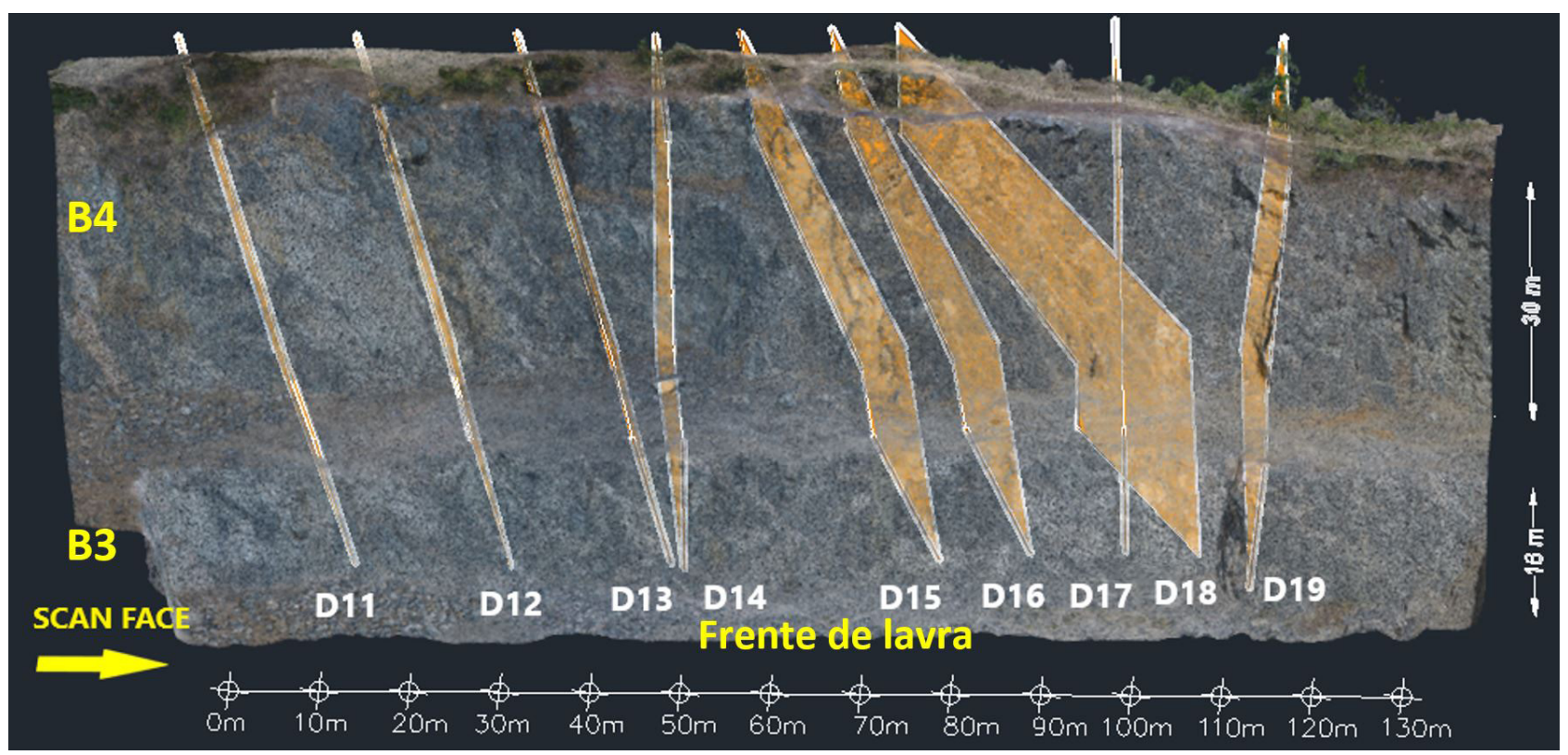

Figura 7. Estimativa do comportamento estrutural das descontinuidades nas bancadas ao leste.

Tabela 1. Atitudes das descontinuidades nas bancadas ao norte

\begin{tabular}{cccc}
\hline DESCONTINUIDADE & DIREÇÃO (Az) & SENTIDO (Az) & MERGULHO \\
\hline D1 & 358 & 88 & 80 \\
D2 & 347 & 77 & 85 \\
D3 & 347 & 77 & 85 \\
D4 & 347 & 77 & 85 \\
D5 & 352 & 82 & 75 \\
D6 & 352 & 262 & 17 \\
D7 & 355 & 85 & 85 \\
D8 & 355 & 265 & 85 \\
D9 & 353 & 83 & 90 \\
D10 & 352 & 262 & 17 \\
\hline
\end{tabular}
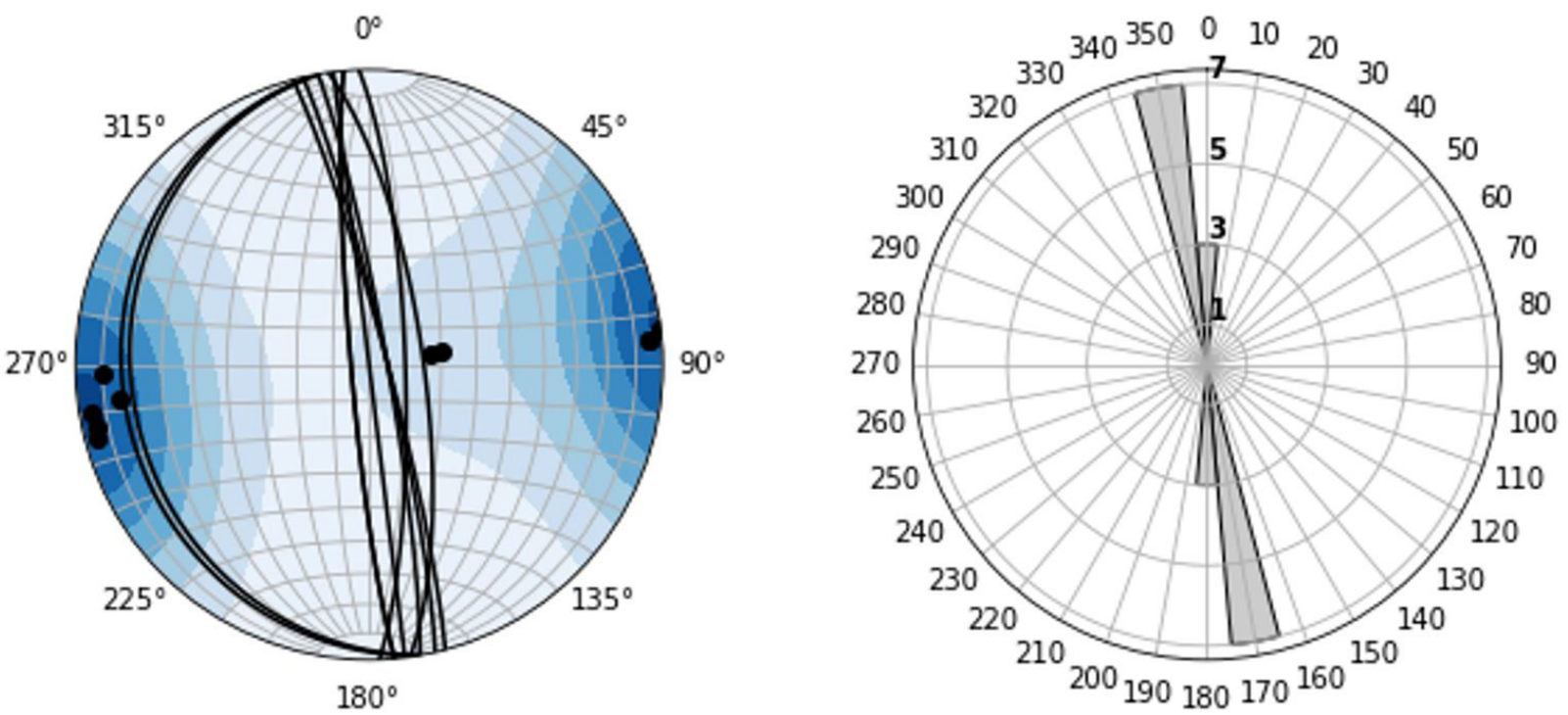

Figura 8. Projeção estereográfica das bancadas norte e o diagrama de rosetas. 
Tabela 2. Atitudes das descontinuidades nas bancadas ao leste

\begin{tabular}{cccc}
\hline DESCONTINUIDADE & DIREÇÃO (Az) & SENTIDO (Az) & MERGULHO \\
\hline D11 & 248 & 158 & 75 \\
D12 & 251 & 161 & 75 \\
D13 & 251 & 161 & 75 \\
D14 & 255 & 165 & 85 \\
D15 & 254 & 164 & 65 \\
D16 & 254 & 164 & 65 \\
D17 & 250 & 160 & 50 \\
D18 & 257 & 167 & 85 \\
D19 & 257 & 347 & 80 \\
\hline
\end{tabular}

Tabela 3. Tabela de frequência de descontinuidades nas bancadas ao norte

\begin{tabular}{cccccc}
\hline \multicolumn{2}{c}{ Classes } & $\begin{array}{c}\text { Frequência } \\
\text { Descontinuidades }\end{array}$ & Frequência Relativa & Frequência Acumulada & $\begin{array}{c}\text { Frequência Relativa } \\
\text { Acumulada }\end{array}$ \\
\hline 0 & 10 & 1 & 0.05 & 1 & 0.05 \\
10 & 20 & 1 & 0.05 & 2 & 0.10 \\
20 & 30 & 2 & 0.10 & 4 & 0.20 \\
30 & 40 & 2 & 0.10 & 6 & 0.30 \\
40 & 50 & 2 & 0.10 & 8 & 0.40 \\
50 & 60 & 3 & 0.15 & 11 & 0.55 \\
60 & 70 & 2 & 0.10 & 13 & 0.65 \\
70 & 80 & 2 & 0.10 & 15 & 0.75 \\
80 & 90 & 2 & 0.10 & 17 & 0.85 \\
90 & 100 & 2 & 0.10 & 19 & 0.95 \\
100 & 110 & 1 & 0.05 & 20 & 1.00 \\
\hline
\end{tabular}

Tabela 4. Tabela de frequência de descontinuidades nas bancadas ao leste

\begin{tabular}{cccccc}
\hline \multicolumn{2}{c}{ Classes } & $\begin{array}{c}\text { Frequência de } \\
\text { Descontinuidades }\end{array}$ & Frequência Relativa & Frequência Acumulada & $\begin{array}{c}\text { Frequência Relativa } \\
\text { Acumulada }\end{array}$ \\
\hline 0 & 10 & 1 & 0.05 & 1 & 0.05 \\
10 & 20 & 2 & 0.10 & 3 & 0.14 \\
20 & 30 & 1 & 0.05 & 4 & 0.19 \\
30 & 40 & 2 & 0.10 & 6 & 0.29 \\
40 & 50 & 2 & 0.10 & 8 & 0.38 \\
50 & 60 & 1 & 0.05 & 9 & 0.43 \\
60 & 70 & 1 & 0.05 & 10 & 0.48 \\
70 & 80 & 2 & 0.10 & 12 & 0.57 \\
80 & 90 & 3 & 0.14 & 15 & 0.71 \\
90 & 100 & 2 & 0.10 & 17 & 0.81 \\
100 & 110 & 2 & 0.10 & 19 & 0.90 \\
110 & 120 & 2 & 0.10 & 21 & 1.00 \\
120 & 130 & 1 & 0.00 & 21 & 1.00 \\
\hline
\end{tabular}

A Figura 11 mostra uma estimativa do comportamento estrutural interno das descontinuidades na frente de lavra da bancada leste, onde se constata a distribuição paralela de duas famílias de descontinuidades compostas por D11, D12 e D13 e uma família composta por D15 e D16. Apenas as descontinuidades D17 e D18 se interceptam as demais componentes estruturais, ilustrando o domínio de fraturas conjugadas conhecidas com Riedel $[3,8]$, ao longo de toda a bancada delimitando menos regiões de fraqueza e formação de blocos de partição maiores.
O potencial geométrico dos blocos de partição formados com os dados adquiridos e tratados, da frente leste, Figura 10, onde, assim como na frente norte, se observa uma conjuntura prismática não regular dos blocos, porém com formação mais integra verticalmente pela ausência de descontinuidades mais horizontais.

As persistências longitudinais, representando a extensão interna das descontinuidades no afloramento, estão representadas nas Figuras 12a e $12 \mathrm{~b}$ respectivamente, onde se pode estimar a projeção de futuras e interceptações entre planos. 

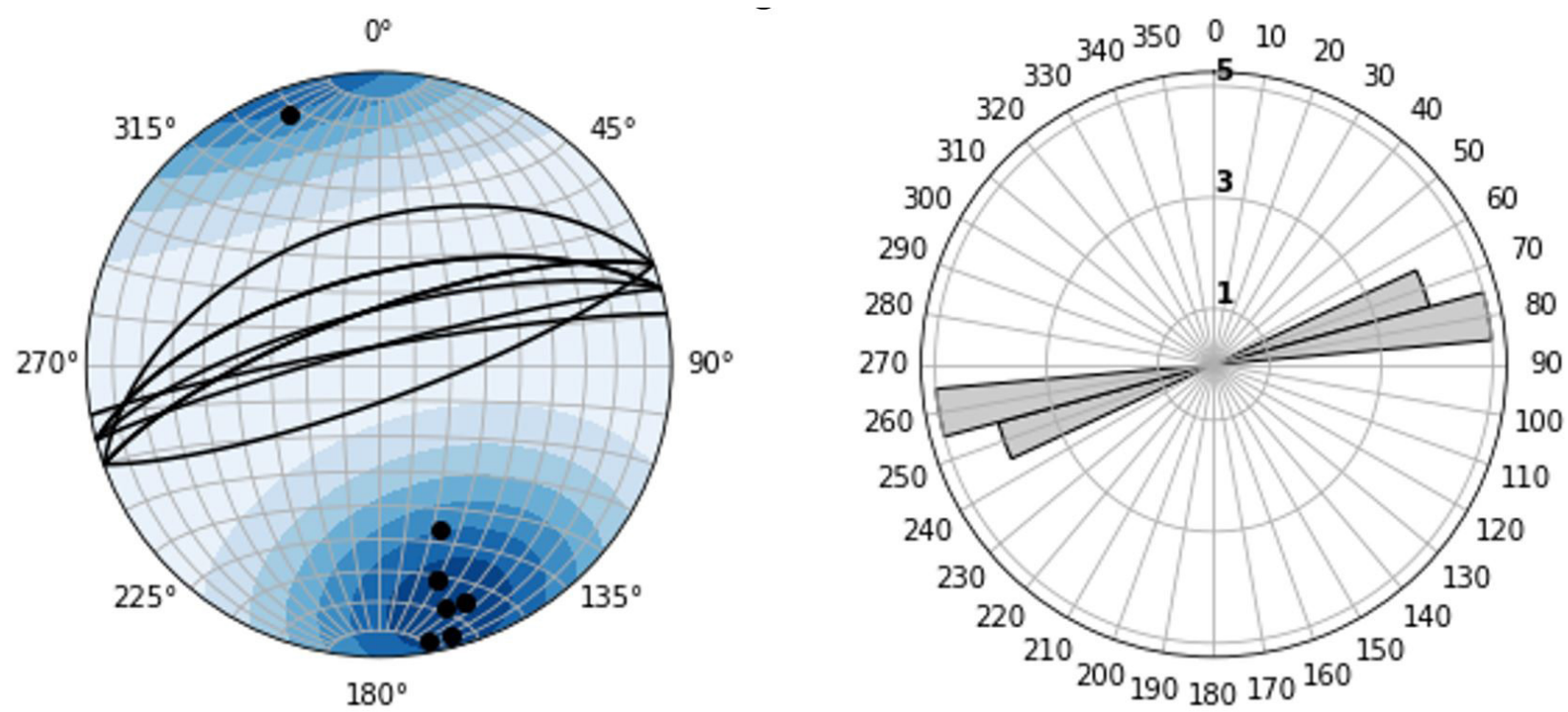

Figura 9. Projeção estereográfica das bancadas leste o diagrama de rosetas.

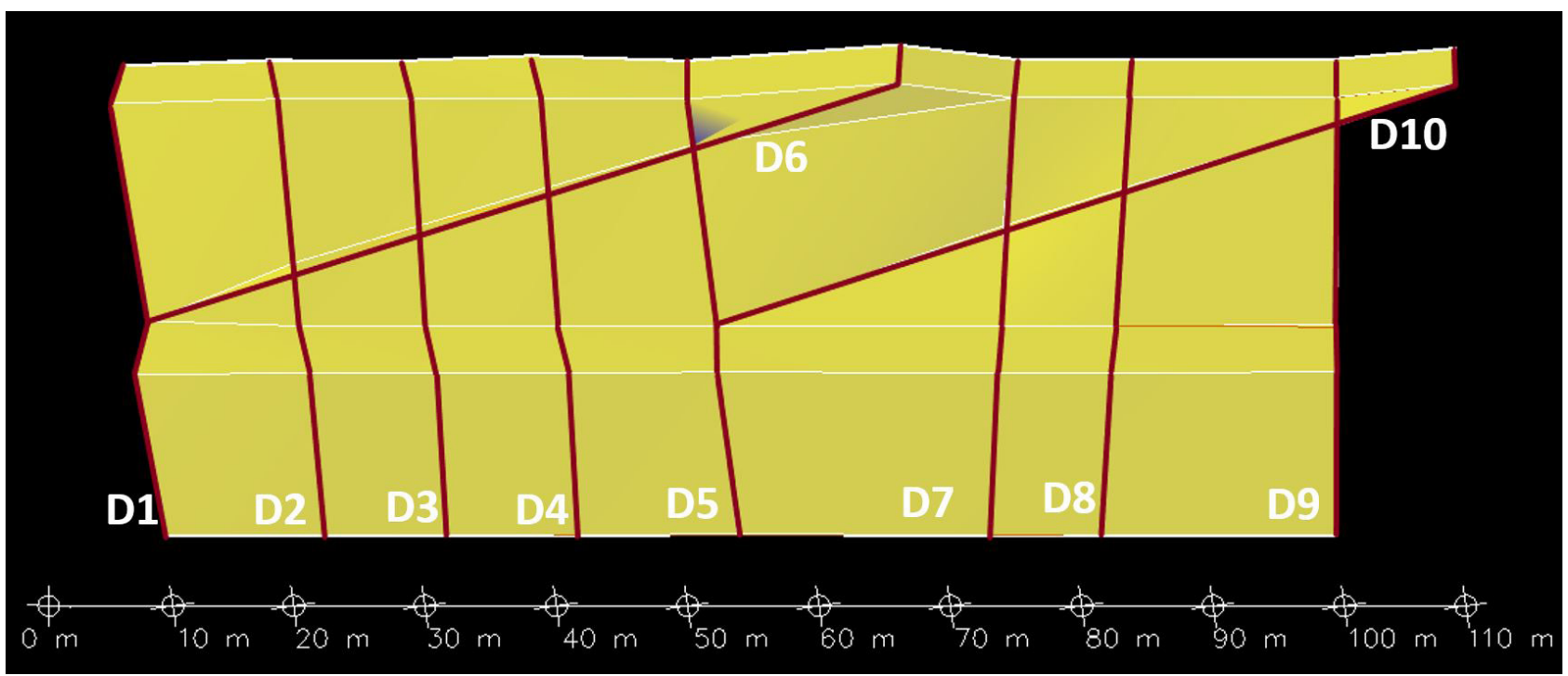

Figura 10. Estimativa dos blocos de partição formados nas bancadas ao norte.

A Figura 13 mostra o resultado do levantamento estatístico descritivo da frequência das descontinuidades nas bancadas norte, com uma distribuição mais uniforme em que os intervalos de (50-60) e (60-70) metros correspondem as regiões mais afetadas com as interceptações dos elementos estruturais D4, D5, D6 e D7, gerando uma região com múltiplos planos de cortes para formação de blocos de partição, e, nas bancadas leste, uma distribuição mais alternada em que os intervalos de (80-90) e (90-100) metros, correspondem as regiões mais afetadas com as interceptações dos elementos estruturais D16, D17 e D18, gerando uma região de fraqueza com múltiplos planos de cortes para formação de blocos de partição.
As bancadas à norte mostram um comportamento oscilatório mais estável em relação as bancadas à leste, devido aos planos de descontinuidade D6 e D10 que interceptam as demais fraturas gerando influência na resistência do maciço nos intervalos delimitados ao longo de toda a bancada.

\section{Conclusão}

O uso do VANT atribui sua vantagem em um melhor tratamento do scan face fazendo destaque das descontinuidades de interesse identificando aquelas com a espessura desejada, sem a necessidade de um corpo técnico presente nas bancadas 


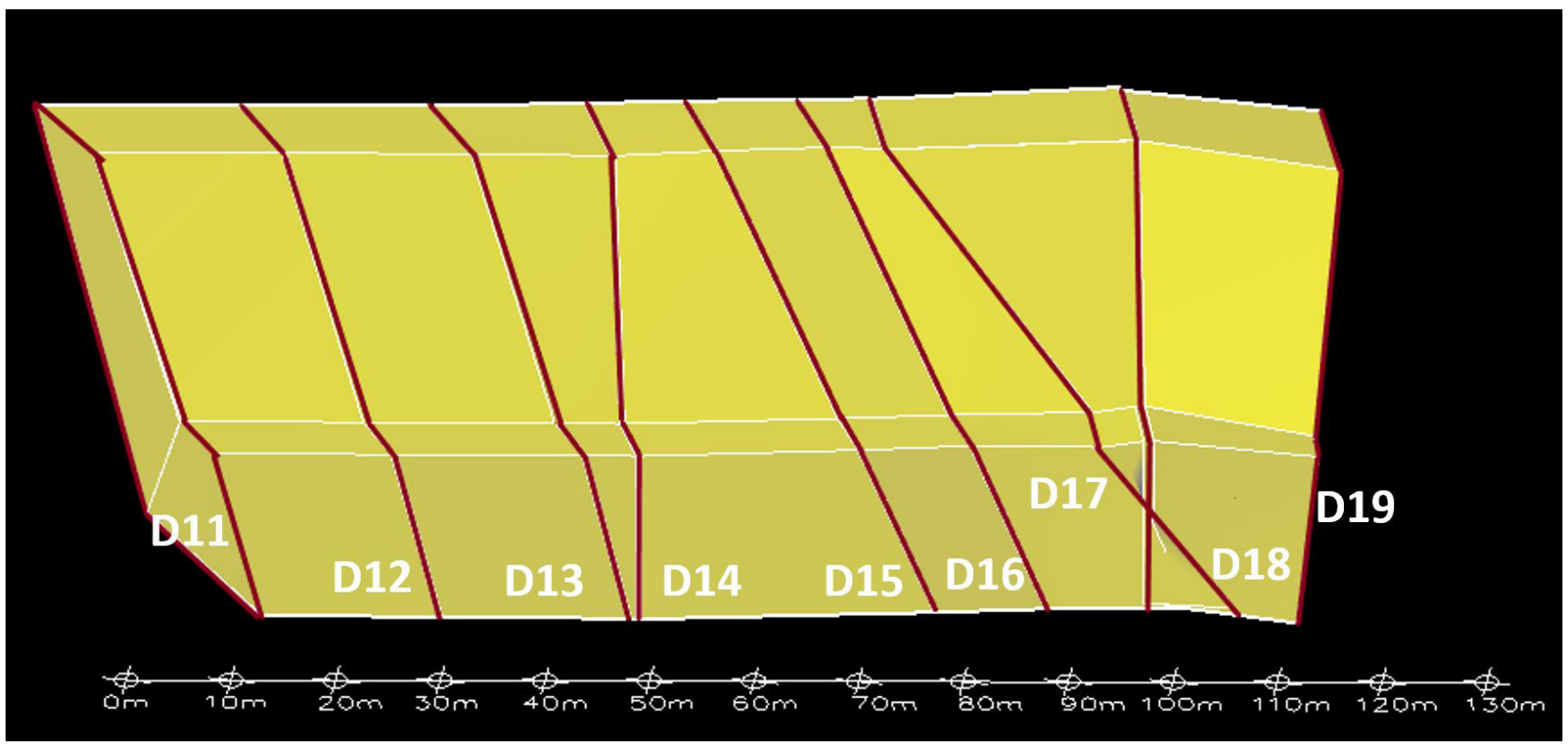

Figura 11. Estimativa dos blocos de partição formados nas bancadas ao leste.
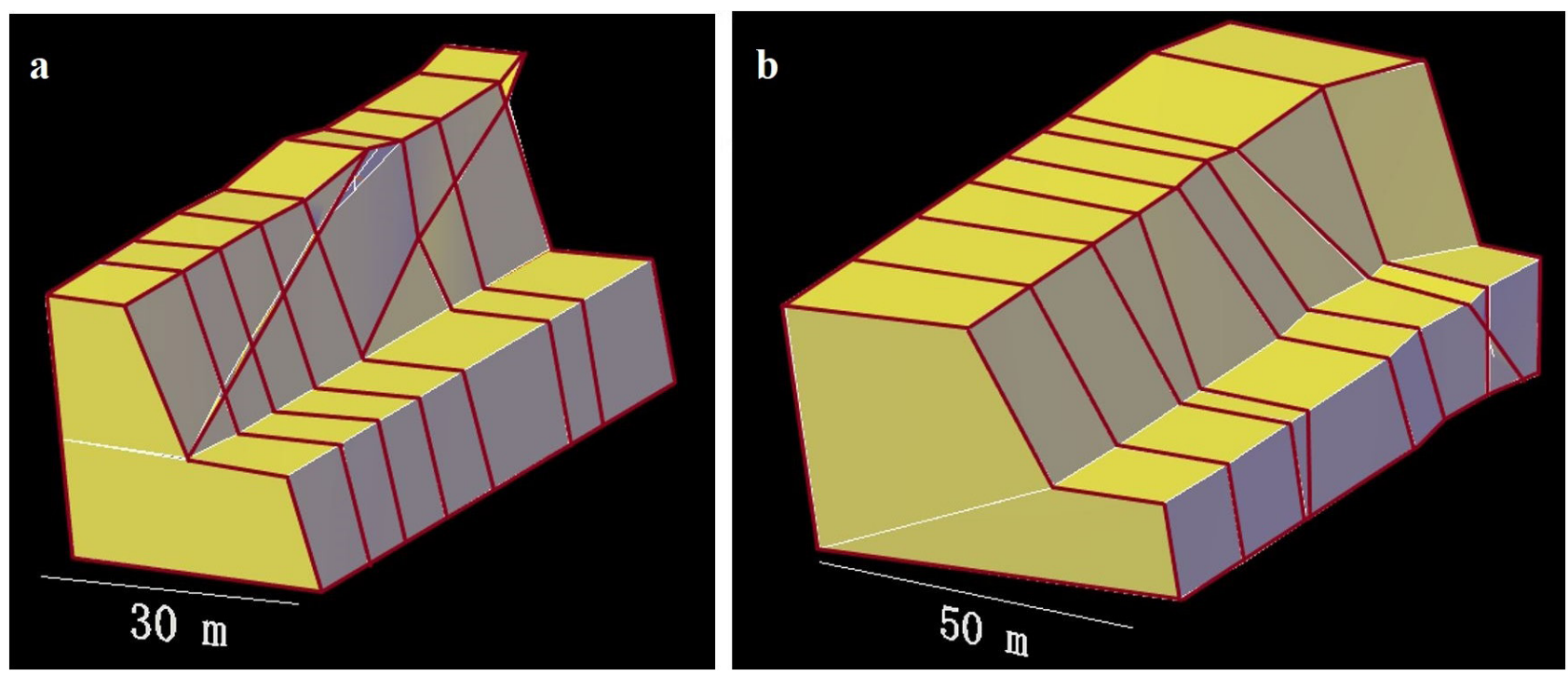

Figura 12. Visualização das estimativas das persistências nas bancadas (a) norte e (b) leste, respectivamente.

para medição das atitudes (direção, sentido e mergulho), e a caracterização das possíveis continuidades dos segmentos dos planos [1,2]. Como também, o aumento do volume dos blocos, identificados pelas persistências longitudinais das descontinuidades.

Em determinados pontos de interseção entre as fraturas ao longo das duas bancadas, foram identificados conjuntos de falhas conjugadas formadas pelo movimento de camadas de rochas subjacentes (embasamento cristalino) na qual, em perfil, exibe uma forma em "X" na zona de cisalhamento, conhecida como fraturas de Riedel [8], identificadas em toda a extensão nas bancadas norte e em um ponto particular nas bancadas leste.
O tratamento estatístico da distribuição de frequência das descontinuidades demonstrou um controle maior em seu arranjo nas bancadas norte, representado pela influência de suas interceptações, e um comportamento mais alternado nas bancadas leste.

A descontinuidades incorporadas na discrição da metodologia, foram adquiridas das bancadas norte e leste mediante a ausência de contaminantes visuais, como por exemplo, fragmentos de processos de desmonte de rochas antecedentes, vegetação e pequenos resquícios de camadas de solos arenosos no topo das bancadas dificultando a identificação das possíveis persistências.

Os blocos de partição formados consideram os dados 


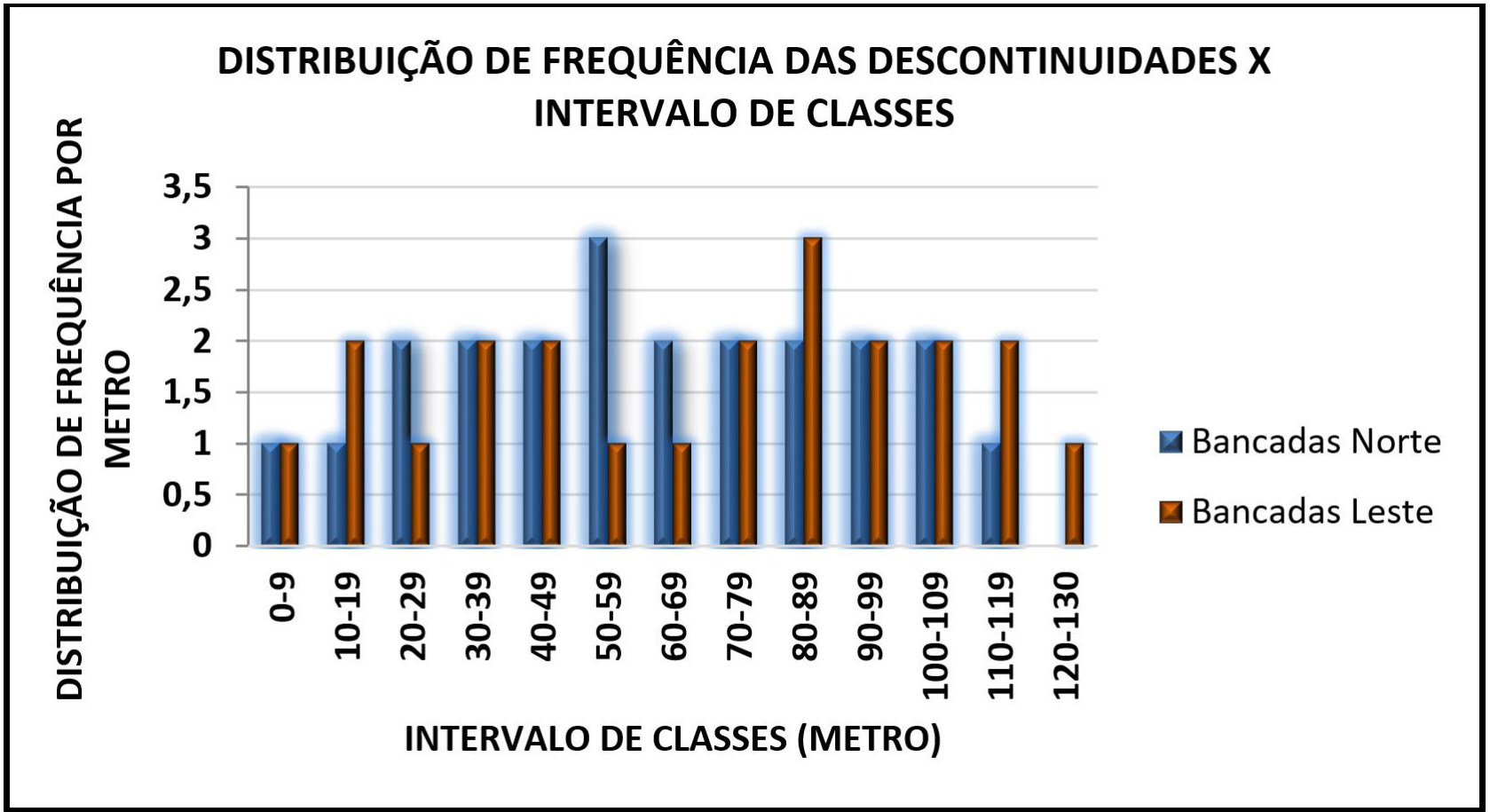

Figura 13. Gráfico com frequência de descontinuidades nas bancadas norte e leste.

citados e tratados no trabalho, que podem alterar sua forma geométrica e seu volume se forem consideradas outras descontinuidades e atitudes das mesmas, e outras persistências longitudinais das fraturas [9]
Essas informações podem auxiliar na identificação de outras zonas de fraqueza e outros blocos que habilitam alterar a interpretação e a intenção do estudo, ocasionando modificações no projeto de engenharia.

\section{Referências}

1 Fiori AP, Carmignani L. Fudamentos de mecânica dos solos e das rochas. Curitiba: UFPR; 2009.

2 Fossen H. Geologia estrutural. São Paulo: Ofinica de Texto; 2012.

3 Oliveira MAS, Brito AS. Geologia de engenharia. São Paulo: ABGE; 1998.

4 Ramírez Oyangüren R, de la Cuadra Irizar L, Laín Huerta R, Grijalbo Obeso E. Mecánica de rocas aplicada a la minería metálicas ubterránea. Madrid: Instituto Geológico y Minero de España; 1984.

5 Fernandes PD. Modelagem semi analítica pseudo tridimensional de propagação e fechamento de fraturas induzidas em rochas [tese]. Campinas: Universidade Estadual de Campinas; 1998.

6 Eisenbeiss H. The potential of unmanned aerial vehicles for mapping. In: Fritsch D, editor. Phogrammetric Week 11. Stuttgart: Institut für Photogrammetrie; 2011. p. 135-144.

7 Comitê Brasileiro de Mecânica das Rochas. Métodos para a descrição quantitativa de descontinuidades em maciços rochosos. São Paulo: ABGE/CBMR; 1983.

8 Araújo ACV. Marcadores de deformação e estágio de deformação com determinação do bloco de partição em pedreiras na Região Metropolitana do Recife [dissertação]. Recife: Universidade Federal de Pernambuco; 2014.

9 Andrade EL. Introdução à pesquisa operacional: métodos e modelos para análise de decisões. 4. ed. Rio de Janeiro: LTC; 2014.

Recebido em: 25 Set. 2019

Aceito em: 3 Maio 2020 